\title{
Molecular analysis of the mouse brain exposed to chronic mild stress: The influence of hepatocyte nuclear factor $4 \alpha$ on physiological homeostasis
}

\author{
KAORU IKUBO $^{1}$, KYOSUKE YAMANISHI ${ }^{1}$, NOBUTAKA DOE ${ }^{2,3}$, TAKUYA HASHIMOTO ${ }^{1}$, \\ MIHO SUMIDA ${ }^{3}$, YUKO WATANABE ${ }^{4}$, YOSIF EL-DARAWISH ${ }^{5}$, WEN LI $^{5}$, \\ HARUKI OKAMURA $^{5}$, HIROMICHI YAMANISHI ${ }^{4}$ and HISATO MATSUNAGA ${ }^{1}$
}

\footnotetext{
${ }^{1}$ Department of Neuropsychiatry and ${ }^{2}$ Laboratory of Neurogenesis and CNS Repair, Hyōgo College of Medicine, Nishinomiya, Hyōgo 663-8501; ${ }^{3}$ Department of Psychology, Hyōgo University of Health Sciences, Kobe, Hyōgo 650-8530;

${ }^{4}$ Hirakata General Hospital for Developmental Disorders, Hirakata, Osaka 573-0122;

${ }^{5}$ Laboratory of Tumor Immunology and Cell Therapy, Hyōgo College of Medicine, Nishinomiya, Hyōgo 663-8501, Japan
}

Received July 27, 2016; Accepted February 27, 2017

DOI: $10.3892 / \mathrm{mmr} .2017 .6577$

\begin{abstract}
Major depressive disorder (MDD) is a prevalent disorder that causes considerable disability in social functioning and is a risk factor for physical diseases. Recent clinical reports have demonstrated a marked association between MDD and physiological dyshomeostasis induced by metabolic disorders, including diabetes, hormone abnormalities and autoimmune diseases. The authors of the present study have previously analyzed comparative gene expression profiles in the prefrontal cortex (PFC) of a chronic mild stress (CMS) animal model of MDD. Hepatocyte nuclear factor $4 \alpha(H n f 4 \alpha)$ was identified as a central regulator that exerted significant influence on genes associated with physiological homeostasis. The aim of the present study was to investigate: i) the molecular mechanism of the depressive state in the PFC,
\end{abstract}

Correspondence to: Professor Hisato Matsunaga, Department of Neuropsychiatry, Hyōgo College of Medicine, 1-1 Mukogawa, Nishinomiya, Hyōgo 663-8501, Japan

E-mail: hisa1311@hyo-med.ac.jp

Abbreviations: ACTB, $\beta$-actin; Ahsg/AHSG, $\alpha 2-\mathrm{HS}$-glycoprotein; $B d n f$, brain-derived neurotrophic factor; CMS, chronic mild stress; $F 2$, coagulation factor II; $H n f 4 \alpha / \mathrm{HNF} 4 \mathrm{~A}$, hepatocyte nuclear factor $4 \alpha ; I g f 1 / \mathrm{IGF} 1$, insulin-like growth factor $1 ; I l / \mathrm{IL}$, interleukin; IPA, Ingenuity Pathway Analysis; MDD, major depressive disorder; PFC, prefrontal cortex; Plg, plasminogen; RT-qPCR, quantitative reverse transcription polymerase chain reaction; S100a9/S100A9, S100 calcium-binding protein A9; Serpina3, serine (or cysteine) peptidase inhibitor, clade A, member 3; Tnfa/TNFA, tumor necrosis factor $\alpha$; Ttr/TTR, transthyretin

Key words: major depressive disorder, depression, hepatocyte nuclear factor $4 \alpha, \quad$ S100 calcium-binding protein A9, $\alpha 2$-HS-glycoprotein, chronic mild stress, physiological homeostasis, prefrontal cortex, thalamus, hippocampus and ii) the involvement of genes extracted from the comparative gene expression profiles, particularly those applicable to MDD in clinical practice. Core analysis of the previous PFC microarray results was performed using Ingenuity Pathway Analysis (IPA). Subsequently, IPA was used to search for molecules that are regulated by $H n f 4 \alpha$, and exist in the PFC and serum. From the core analysis, 5 genes that are associated with cell death and are expressed in the cortex were selected. Four of the extracted genes, insulin-like growth factor 1, transthyretin, serpin family A member 3 and plasminogen, were markedly affected by $H n f 4 \alpha$. S100 calcium-binding protein A9 (S100a9) and $\alpha 2$-HS-glycoprotein (Ahsg) were also chosen as they exist in serum and are also affected by $H n f 4 \alpha$. A significant group difference in the expression of these two genes was detected in the PFC, thalamus and hippocampus. The protein levels of AHSG and S100A9 in the $\mathrm{PFC}$ and hippocampus of the CMS group increased significantly when compared with the control group. These findings support the close association of $\mathrm{Hnf} 4 \mathrm{\alpha}$ (through genes such as S100a9 and Ahsg) with the development of various diseases induced by deregulation of physiological homeostasis during the progression of MDD.

\section{Introduction}

Major depressive disorder (MDD) is one of the most prevalent mental disorders in developed countries such as Japan, and its frequency is rapidly increasing $(1,2)$. However, the etiological and psychobiological mechanisms for the development of MDD remain unclear, even though pharmacological agents for MDD have been extensively investigated, with a particular focus on serotonergic, adrenergic and/or dopaminergic dysfunction (3). Clinical and basic research of depressive status has indicated that there are close associations and strong interactions among the prefrontal cortex (PFC), thalamus and hippocampus (4-7). For example, stressful conditions increase activity in the PFC and limbic or prelimbic regions, resulting in hyperactivity of the hypothalamic-pituitary-adrenal axis 
and hippocampus $(4,5)$. Despite such associations between these parts of the brain in healthy people and in depressive subjects, the mechanism underlying their interactions remains unknown.

Previous studies have indicated significant associations between MDD and biomarkers that can be detected in serum, including cytokines, brain-derived neurotrophic factor (BDNF) and hormones in patients treated with corticosteroids or interferon therapy (8-12). For example, levels of serum BDNF decreased and levels of inflammatory cytokines increased in patients with MDD (13-15). However, these factors were also affected by diurnal variation or by physical conditions $(16,17)$. Therefore, there is still insufficient evidence to support their validity and applicability as diagnostic markers or as biological indicators for assessing the severity of MDD. Thus, even though MDD is a disorder associated with psychological, sociocultural or neurobiological factors and also with more pervasive physiological dysfunctions, the underlying mechanisms for interactions between these factors have yet to be elucidated.

The group have previously performed molecular analyses to assess the associations between MDD and dysregulation of physiological homeostasis. Hepatocyte nuclear factor $4 \alpha(H n f 4 \alpha)$ was identified as a candidate central regulator that has crucial influence on immunological function, lipid metabolism, coagulation, hormonal activity and the synthesis of amines (18). As $H n f 4 \alpha$ is a transcription factor, it is difficult to measure in serum, and the target molecules regulated by $H n f 4 \alpha$ that are detectable in serum have not been examined. Therefore, the influence of $H n f 4 \alpha$ on the development of clinical MDD or depressive status in humans has not been determined.

The aim of the present study was to investigate: i) the molecular mechanism of the depressive state in the PFC; and ii) the involvement of genes extracted from comparative gene expression analysis that may mediate the associations between MDD and physiological diseases using a chronic mild stress (CMS) animal model of MDD. In addition, the present study determined whether specific molecules regulated by $\mathrm{Hnf} 4 \alpha$ may exist in the PFC and serum, and examined the possibility that these molecules may be reliable indicators of clinical MDD.

\section{Materials and methods}

Details regarding the experimental animals, the CMS procedure, sample collection, RNA purification, microarray analysis, reverse transcription-quantitative polymerase chain reaction (RT-qPCR), western blotting and Ingenuity Pathway Analysis (IPA) have been described in our previous studies $(18,19)$.

Animals. A total of 50 experimentally naïve male C57BL/6N mice (Japan SLC, Inc., Shizuoka, Japan) were used. Mice were 9-10 weeks old and weighed $22.3 \mathrm{~g}$ on average at the start of the experiment. Mice were housed in groups of 3, 4 or 5 in polycarbonate cages that were placed in a colony room maintained at a constant temperature $\left(22 \pm 1^{\circ} \mathrm{C}\right)$ and humidity (50-60\%), under a 12-h light/dark cycle (lights on at 7:00 am) with free access to food and water.

Animals were randomly assigned to one of two groups: The control group ( $\mathrm{C}$ group) mice and the chronic mildly stressed (CMS) group mice, as previously described (18). The procedure to induce CMS is described in Table I and was performed over 4 weeks. A total of 16 mice from each group were euthanized by decapitation using a guillotine, and brain samples were collected for molecular analyses.

Animal experiments were conducted according to the Guide for Care and Use of Laboratory Animals published by the National Institutes of Health, and was approved by the Ethical committee of Behavioral and Medical Science Research Consortium (Hyōgo, Japan; approval IDs: 2012-B-09 and 2012-B-10). All efforts were made to minimize the number of mice used and the suffering of animals.

RNA purification. Total RNA was purified from the mouse brain using a Sepasol-RNA I Super kit (Nacalai Tesque, Inc., Kyoto, Japan), according to the manufacturer's instructions, and was treated with 5 units of RNase-free DNase I at $37^{\circ} \mathrm{C}$ for $30 \mathrm{~min}$ to remove genomic DNA contamination. Following phenol/chloroform (Wako Pure Chemical Industries, Ltd., Osaka, Japan) extraction and $100 \%$ ethanol (Wako Pure Chemical Industries, Ltd.) precipitation, as previously described $(18,19)$, total RNA was dissolved in deionized distilled water. RNA concentrations were determined using a NanoDrop-1000 spectrophotometer (NanoDrop Technologies; Thermo Fisher Scientific, Inc., Pittsburgh, PA, USA).

Microarray analysis. The microarray analysis of the whole genome was outsourced to Takara Bio, Inc. (Mie, Japan). The protocol details are described below (series entry, GSE49867).

RNA quality check. RNA was re-quantified using a NanoDrop2000 spectrophotometer (NanoDrop Technologies; Thermo Fisher Scientific, Inc.), according to the manufacturer's protocol, and the quality was monitored with an Agilent 2100 Bioanalyzer (Agilent Technologies, Inc., Santa Clara, CA, USA).

Labeling protocol (1 color). Cyanine-3 (Cy3)-labeled cRNA was prepared from $0.1 \mu \mathrm{g}$ total RNA using the Low Input Quick Amp Labeling kit (Agilent Technologies, Inc.), followed by RNeasy column purification (Qiagen, Inc., Valencia, CA, USA), according to the manufacturer's protocol. Dye incorporation and the cRNA yield were checked with a NanoDrop ND-2000 spectrophotometer (NanoDrop Technologies; Thermo Fisher Scientific, Inc.).

Hybridization protocol. A total of $0.6 \mu \mathrm{g}$ Cy3-labeled cRNA was fragmented at $60^{\circ} \mathrm{C}$ for $30 \mathrm{~min}$ in a reaction volume of $25 \mu \mathrm{l}$ containing $1 \mathrm{X}$ Agilent fragmentation buffer and $2 \mathrm{X}$ Agilent blocking agent, following the manufacturer's instructions (Agilent Technologies, Inc.). Upon completion of the fragmentation reaction, $25 \mu \mathrm{l} 2 \mathrm{X}$ Agilent hybridization buffer was added to the fragmentation mixture and hybridized to an Agilent SurePrint G3 Mouse GE 8x60 K array (cat. no. G4858A-028005) for $17 \mathrm{~h}$ at $65^{\circ} \mathrm{C}$ in a rotating Agilent hybridization oven (Agilent Technologies, Inc.).

Following hybridization, microarrays were washed for $1 \mathrm{~min}$ at room temperature with GE Wash buffer 1 (Agilent Technologies, Inc.) and for $1 \mathrm{~min}$ at $37^{\circ} \mathrm{C}$ with GE Wash buffer 2 (Agilent Technologies, Inc.). 
Table I. Weekly schedule for the induction of chronic mild stress.

\begin{tabular}{lll}
\hline Day & \multicolumn{1}{c}{ Light phase } & \multicolumn{1}{c}{ Dark phase } \\
\hline 1 & Water deprivation $(8 \mathrm{~h}) /$ isolation & Changed room/isolation \\
2 & Isolation $(12 \mathrm{~h})$ & Overnight illumination $(36 \mathrm{~h})$ \\
3 & A wet cage $(4 \mathrm{~h}) /$ isolation $(12 \mathrm{~h})$ & Changed room/isolation \\
4 & Cage tilt $(8 \mathrm{~h}) /$ isolation $(12 \mathrm{~h})$ & Changed room/isolation \\
5 & Physical restraint $(4 \mathrm{~h}) /$ isolation $(12 \mathrm{~h})$ & Changed room/isolation \\
6 & Forced swimming $(30 \mathrm{mins}) /$ isolation $(12 \mathrm{~h})$ & Changed room/isolation \\
7 & Electric shocks $(60$ times $) /$ isolation $(12 \mathrm{~h})$ & Changed room/isolation
\end{tabular}

Animals were randomly assigned to one of two groups: The control group and the chronic mildly stressed mice group, as previously described (16). The Table describes the weekly procedure to induce CMS, which was repeated 4 times and was performed over 4 weeks.

Scanning protocol. Following washing, slides were immediately scanned on the Agilent DNA Microarray Scanner (cat. no. G2565CA; Agilent Technologies, Inc.) using a one-color scan setting for $8 \times 60 \mathrm{~K}$ array slides (scan area, $61 \times 21.6 \mathrm{~mm}$; scan resolution, $3-\mu \mathrm{m}$; the dye channel set was to green, and the green photomultipier was set to $100 \%$ ).

Data processing. The scanned images were analyzed with Feature Extraction Software v10.10.1.1 (Agilent Technologies, Inc.) using default parameters to obtain background subtracted and spatially detrended processed signal intensities.

Value definition. Scaled signal intensities were adjusted to an average intensity value of 2,500 (in arbitrary units).

IPA. Microarray data were analyzed using IPA software version spring 2016 (Ingenuity ${ }^{\circledR}$ Systems; http://www.ingenuity.com), to provide functionality for the interpretation of gene expression data. The network explorer of IPA was used to identify relevant interactions, functions and diseases among the CMS and C group genes, and to determine the shortest direct paths between genes. Firstly, to investigate the molecular mechanism of MDD and the influence of $H n f 4 \alpha$, core analysis settings of microarray results were performed as follows: Network, Interaction; Data Sources, all; Confidence, Experimentally Observed; Species, human and mice; Tissues, Cerebral cortex; Mutation, all. Subsequently, for investigating novel molecules that are able to be detected in serum, core analysis settings were set to default. Analysis was performed as described in our previous studies $(18,19)$.

$R T-q P C R$. To validate the results obtained by the microarray analysis and IPA, RT-qPCR was performed. Total RNA (10 ng/reaction) extracted from the CMS and C groups was used with the RNA-direct SYBR ${ }^{\circledR}$ Green Real-Time PCR Master mix: One-step qPCR kit (Toyobo Co., Ltd., Osaka, Japan), according to manufacturer's protocol. Samples were run in duplicate reactions in 96-well plates. Median threshold cycle values were used to calculate fold changes (FCs) between the samples of the two groups. FC values were normalized to GAPDH expression, using the relative standard curve method. qPCR was performed using an Applied Biosystems 7500 Real-Time PCR System (Thermo Fisher Scientific, Inc.), under the following thermocycling conditions: $30 \mathrm{sec}$ at $90^{\circ} \mathrm{C}$ and $20 \mathrm{~min}$ at $61^{\circ} \mathrm{C}$ for reverse transcription according to the manufacturer's protocol, followed by 45 cycles of $98^{\circ} \mathrm{C}$ for $1 \mathrm{sec}, 67^{\circ} \mathrm{C}$ for $15 \mathrm{sec}$ and $74^{\circ} \mathrm{C}$ for $35 \mathrm{sec}$. The primer sequences for RT-qPCR are presented in Table II, and the production of these primers was outsourced to Sigma-Aldrich; Merck KGaA (Darmstadt, Germany).

Western blotting. For western blotting, mouse brains were minced in Lysis buffer [1\% Nonidet P-40, 20 mM Tris- $\mathrm{HCl}$ (pH 8.0), $150 \mathrm{mM} \mathrm{NaCl}, 10 \%$ glycerol] containing a protease inhibitor cocktail (Complete ${ }^{\mathrm{TM}}$; Roche Diagnostics, Tokyo, Japan). They were then homogenized on ice using a sonicator (Sonifier II; Branson; Emerson Ultrasonics, CT, USA), and each lysate was centrifuged at $4^{\circ} \mathrm{C}$ in $13,000 \mathrm{x}$ g for $3 \mathrm{~min}$ and the supernatant was collected. The protein concentration in each specimen was determined with a Bradford protein assay kit (Bio-Rad Laboratories, Inc., Hercules, CA, USA), according to the manufacturer's protocol. Samples were denatured in Laemmli's sample buffer (cat. no. \#09499-14; Nacalai Tesque, Inc.) for $5 \mathrm{~min}$ at $95^{\circ} \mathrm{C}$, electrophoresed in a $12.5 \%$ sodium dodecyl sulfate polyacrylamide gel, and transferred onto a polyvinylidene difluoride membrane (Hybond-P; Amersham; GE Healthcare Life Sciences, Chalfont, UK). Membranes were blocked for $1 \mathrm{~h}$ at room temperature with $1 \%$ bovine serum albumin in phosphate-buffered saline (PBS) containing $0.1 \%$ Triton X-100 (T-PBS), then incubated with primary antibodies at $4^{\circ} \mathrm{C}$ overnight. The membranes were probed with polyclonal rabbit anti-insulin-like growth factor 1 (IGF1; dilution 1:100; cat. no. \#NBP1-45641; Novus Biologicals, LLC, Littleton, CO, USA), polyclonal rabbit anti-transthyretin (TTR; dilution 1:200; cat. no. sc-13098; Santa Cruz Biotechnology, Inc., Dallas, TX, USA), polyclonal rabbit anti-S100 calcium-binding protein A9 (S100A9; dilution 1:1,000; cat. no. \#NB110-89726; Novus Biologicals, LLC), polyclonal rabbit anti- $\alpha 2-\mathrm{HS}$-glycoprotein (AHSG; dilution 1:250; cat. no. \#bs-2922R; BIOSS, Beijing, China), monoclonal rabbit anti- $\beta$-actin (ACTB; dilution 1:1,000; cat. no. \#5125S; Cell Signaling Technology, Inc., Danvers, MA, USA) and monoclonal rabbit anti-GAPDH (dilution 1:1,000; cat. no. \#3683S; Cell Signaling Technology, Inc.) antibodies. Membranes were then incubated for $3 \mathrm{~h}$ at room temperature with horseradish peroxidase-conjugated donkey anti-rabbit immunoglobulin G secondary antibody (dilution 1:2,000; cat. 
Table II. Primer sequences used for reverse transcription-quantitative polymerase chain reaction.

\begin{tabular}{|c|c|c|c|}
\hline Gene & GenBank accession no. & Type & Primer sequence $\left(5^{\prime} \rightarrow 3^{\prime}\right)$ \\
\hline Ahsg & NM_011994 & $\begin{array}{l}\text { Sense } \\
\text { Anti-sense }\end{array}$ & $\begin{array}{l}\text { CATAAAGCCAGCAGCAACACT } \\
\text { AGAGCACCTTTCAGAGTCGT }\end{array}$ \\
\hline$F 2$ & NM_010168 & $\begin{array}{l}\text { Sense } \\
\text { Anti-sense }\end{array}$ & $\begin{array}{l}\text { CTTACCAGCCAAGACCCT } \\
\text { AGTTTTCCACGAGTTTCACC }\end{array}$ \\
\hline Gapdh & NM_008084 & $\begin{array}{l}\text { Sense } \\
\text { Anti-sense }\end{array}$ & $\begin{array}{l}\text { CCTTCCGTGTTCCTACCCCCAAT } \\
\text { TTGATGTCATCATACTTGGCAGGTTTCTC }\end{array}$ \\
\hline $\operatorname{Igfl}$ & NM_010512 & $\begin{array}{l}\text { Sense } \\
\text { Anti-sense }\end{array}$ & $\begin{array}{l}\text { ATTTCCAGACTTTGTACTTCAGAAGCGATG } \\
\text { TCACAGAGGCAGATCTTAAATAATTGAGT }\end{array}$ \\
\hline Plg & NM_008877 & $\begin{array}{l}\text { Sense } \\
\text { Anti-sense }\end{array}$ & $\begin{array}{l}\text { TCGCTGGATGGCTACATAAGCACA } \\
\text { GCCAAACAGTCCGAGACACC }\end{array}$ \\
\hline $5100 a 9$ & NM_007631 & $\begin{array}{l}\text { Sense } \\
\text { Anti-sense }\end{array}$ & $\begin{array}{l}\text { GCAGCATAACCACCATCATCGAC } \\
\text { CTGTGCTTCCACCATTTGTCTGA }\end{array}$ \\
\hline$T t r$ & NM_013697 & $\begin{array}{l}\text { Sense } \\
\text { Anti-sense }\end{array}$ & $\begin{array}{l}\text { CCTGCTCAGCCCATACTCCT } \\
\text { CTTTGGCAAGATCCTGGTCCTC }\end{array}$ \\
\hline
\end{tabular}

Ahsg, a2-HS-glycoprotein; F2, coagulation factor II; Igf1, insulin-like growth factor 1; Plg, plasminogen; Serpina3, serine (or cysteine) peptidase inhibitor, clade A, member 3; S100a9, S100 calcium-binding protein A9; Ttr, transthyretin.

no. \#NA9340V; GE Healthcare Life Sciences). Washing with T-PBS was performed following each treatment. Antibody reactions were captured using the photo-image analyzer, LAS-4010 (Fujifilm Corporation, Tokyo, Japan). The density of specific protein bands was measured twice using ImageJ software version 1.6 (National Institutes of Health, Bethesda, MD, USA). AHSG and S100A9 expression was normalized to GAPDH, whereas IGF1 and TTR expression was normalized to ACTB. The mean of the measured bands in controls was set to one. The present study also assessed HL-60 whole cell lysate (cat. no. \#NB800-PC3, Novus Biologicals, LLC) and mature liver lysate, isolated from the same mice, as positive controls of S100A9 and AHSG, respectively.

Statistical analysis. All results are expressed as the mean \pm standard deviation. Sigmaplot ${ }^{\mathrm{TM}}$ (version 11.0; Systat Software, Inc., San Jose, CA, USA) was used for all statistical analyses. Differences between the two groups were analyzed by Student's t-test or the Mann-Whitney U-test. $\mathrm{P}<0.05$ was considered to indicate a statistically significant difference. All analyses were performed $>2$ times to confirm the results.

\section{Results}

Isolation and classification of cortex-specific genes in CMS mice. The microarray results have been published previously (18). A total of 494 genes whose expression was $>2 \mathrm{X}$ or $<1 / 2$ that of the $\mathrm{C}$ group were extracted from the CMS group. The IPA results from the microarray data using the first settings are shown in Table III. In this analysis, 5 genes were identified, coagulation factor II $(F 2)$, Igfl, plasminogen (Plg), Ttr and serine (or cysteine) peptidase inhibitor, clade A, member 3 (Serpina3). In addition, Igfl, Plg, Serpina3 and Ttr were affected by $H n f 4 \alpha$ (Fig. 1A).
Investigation of novel genes with a connection between depression and physiological homeostasis. To investigate novel molecules that are associated with physiological homeostasis, are able to be detected in serum and are regulated directly by $H n f 4 \alpha$, a number of molecules from all of the extracted genes were chosen automatically (Fig. 1B). In the present study, the main focus was the analysis of S100a9 and Ahsg as they were directly affected by only Hnf4a (thus excluding multiple regulation) and may be detected in serum with simple probes in microarray analysis.

IPA analysis of 494 genes indicated that S100a9 and Ahsg may affect the development of a number of physical diseases. S100a9 affects arteriosclerosis associated with vascular diseases or ischemia of the brain and rheumatic diseases (Table IV). Ahsg is associated with lipid concentration, rheumatic diseases and glucose tolerance (Table V).

$R T$-qPCR. Previously, Spearman's rank collection test identified a significant correlation between the microarray and RT-qPCR data for S100a9 and Ahsg in the PFC (18). Additional comparisons for F2, Igfl, Plg and Ttr in the PFC between groups are shown in Table VI. S100a9 expression was significantly decreased in the hippocampus, although not in the thalamus (Fig. 2A). By contrast, Ahsg expression was significantly increased in the thalamus, although not in the hippocampus (Fig. 2B).

Western blotting. When the protein levels of IGF1 and TTR were measured in the PFC, thalamus and hippocampus, no differences were observed between the $\mathrm{C}$ and CMS groups (Fig. 3A-C). The augmented expression of S100A9 and AHSG in the PFC, thalamus and hippocampus of CMS mice was further examined. In accordance with the microarray and RT-qPCR results, quantitative analysis of the representative blots indicated enhanced synthesis of these two proteins in 
Table III. Disease or function annotation of the prefrontal cortex.

\begin{tabular}{lcc}
\hline Disease or function annotation & P-value & Molecules \\
\hline Height of barrel cortex & $7.93 \mathrm{E}-03$ & Igfl \\
Uptake of D-glucose & $7.93 \mathrm{E}-03$ & $\operatorname{Igfl}$ \\
Volume of barrel cortex & $7.93 \mathrm{E}-03$ & Igfl \\
Cell death & $1.22 \mathrm{E}-02$ & F2, Igf1, Plg, Serpina3, Ttr \\
Area of barrel cortex & $1.58 \mathrm{E}-02$ & Igfl \\
First-onset paranoid schizophrenia & $1.58 \mathrm{E}-02$ & Ttr \\
Proliferation of endothelial cells & $2.36 \mathrm{E}-02$ & Igfl \\
Density of blood vessel & $3.90 \mathrm{E}-02$ & Igfl \\
Synaptic transmission of cortical neurons & $3.90 \mathrm{E}-02$ & Igfl \\
Cell death of cerebral cortex cells & $4.35 \mathrm{E}-02$ & F2; hippocampal neurons, Igfl \\
& & and Serpina3; cortical neurons
\end{tabular}

Igfl, insulin-like growth factor 1; F2, coagulation factor II; Plg, plasminogen; Serpina3, serine (or cysteine) peptidase inhibitor, clade A, member 3; Ttr, transthyretin.

Table IV. Disease or function annotation of S100 calciumbinding protein A9.

\begin{tabular}{ll}
\hline Disease or function annotation & P-value \\
\hline Accumulation of macrophages & $3.44 \mathrm{E}-04$ \\
Accumulation of phagocytes & $1.07 \mathrm{E}-04$ \\
Activation of antigen presenting cells & $2.29 \mathrm{E}-04$ \\
Activation of leukocytes & $2.62 \mathrm{E}-05$ \\
Activation of macrophages & $5.68 \mathrm{E}-04$ \\
Activation of phagocytes & $7.81 \mathrm{E}-05$ \\
Adhesion of neutrophils & $3.44 \mathrm{E}-04$ \\
Adhesion of phagocytes & $6.25 \mathrm{E}-04$ \\
Binding of neutrophils & $1.63 \mathrm{E}-05$ \\
Binding of phagocytes & $2.41 \mathrm{E}-05$ \\
Immune response of cells & $1.04 \mathrm{E}-04$ \\
Inflammation of organ & $8.64 \mathrm{E}-08$ \\
Inflammatory response & $5.10 \mathrm{E}-08$ \\
Ischemia of brain & $9.69 \mathrm{E}-05$ \\
Phagocytosis of blood cells & $7.18 \mathrm{E}-04$ \\
Phagocytosis of cells & $3.68 \mathrm{E}-04$ \\
Rheumatic disease & $5.06 \mathrm{E}-06$ \\
Rheumatoid arthritis & $7.08 \mathrm{E}-04$ \\
Systemic autoimmune syndrome & $9.69 \mathrm{E}-05$ \\
\hline
\end{tabular}

the PFC of the CMS mice. S100A9 expression in the PFC of the CMS group was higher compared with that in the $\mathrm{C}$ group (Fig. 4A and B). In contrast with the mRNA levels in the hippocampus, S100A9 levels were significantly higher in the hippocampus of CMS mice when compared with those of the C group; however, there was no difference in S100A9 levels in the thalamus (Fig. 4A and B). Similar to the microarray and RT-qPCR results, ASHG levels in the PFC of the CMS group were significantly increased when compared with those in the $\mathrm{C}$ group (Fig. 4A and C). By contrast, no difference was observed in the thalamus or hippocampus (Fig. 4A and C).

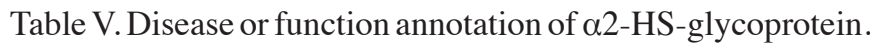

\begin{tabular}{lc}
\hline Disease or function annotation & P-value \\
\hline Arteriosclerosis & $4.35 \mathrm{E}-12$ \\
Arthritis & $3.42 \mathrm{E}-05$ \\
Arthropathy & $1.95 \mathrm{E}-05$ \\
Concentration of lipid & $5.73 \mathrm{E}-25$ \\
Concentration of triacylglycerol & $2.06 \mathrm{E}-17$ \\
Immune response of cells & $1.04 \mathrm{E}-04$ \\
Inflammatory response & $5.10 \mathrm{E}-08$ \\
Insulin resistance & $3.96 \mathrm{E}-09$ \\
Phagocytosis & $2.80 \mathrm{E}-04$ \\
Phagocytosis of cells & $3.68 \mathrm{E}-04$ \\
Rheumatic disease & $5.06 \mathrm{E}-06$ \\
Rheumatoid arthritis & $7.08 \mathrm{E}-04$ \\
Systemic autoimmune syndrome & $9.69 \mathrm{E}-05$ \\
Vascular disease & $2.93 \mathrm{E}-12$ \\
\hline
\end{tabular}

\section{Discussion}

The present study revealed the following clinical and pathophysiological features of MDD: i) $F 2$ and $P l g$, which are strongly regulated by $H n f 4 \alpha$, and Serpina 3 may be induced in the depressive state PFC through $H n f 4 \alpha$; and ii) S100A9 and AHSG are potential biomarkers for the development of physical disease in patients with MDD.

A total of 5 genes, F2, Igf1, Plg, Serpina3 and Ttr, were extracted from the IPA analyses according to the molecular mechanisms of MDD in the PFC. As shown in Table III, 2 out of 10 annotations, 'cell death of cerebral cortex cells' and 'cell death', were associated with cell death processes such as apoptosis (20-25). F2, Plg and Serpina3 may increase 'cell death', and F2 and Serpina3 may also be associated with 'apoptosis of neurons' (23-25). F2 and Plg were categorized as 'coagulation', whose dysfunction may be closely associated 
Table VI. Comparison of gene expression levels as determined by microarray and reverse transcription-quantitative polymerase chain reaction experiments.

\begin{tabular}{lccc}
\hline $\begin{array}{l}\text { GenBank } \\
\text { accession no. }\end{array}$ & $\begin{array}{c}\text { Gene } \\
\text { symbol }\end{array}$ & $\begin{array}{c}\text { FC } \\
\text { (RT-qPCR) }\end{array}$ & $\begin{array}{c}\text { FC } \\
\text { (microarray) }\end{array}$ \\
\hline NM_010168 & F2 & 3.613 & 7.650 \\
NM_010512 & Igfl & 1.482 & 3.568 \\
NM_008877 & Plg & 5.407 & 8.441 \\
NM_013697 & Ttr & 8.338 & 10.494 \\
\hline
\end{tabular}

FC, fold change; Igfl, insulin-like growth factor $1 ; F 2$, coagulation factor II; Plg, plasminogen; Serpina3, serine (or cysteine) peptidase inhibitor, clade A, member 3; Ttr, transthyretin. RT-qPCR, reverse transcription-quantitative polymerase chain reaction.

A

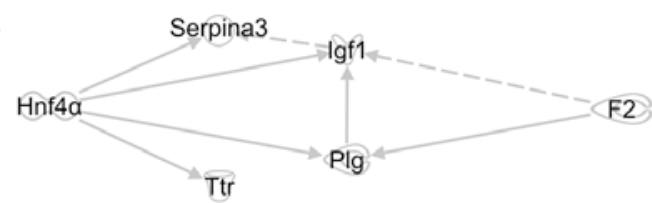

B

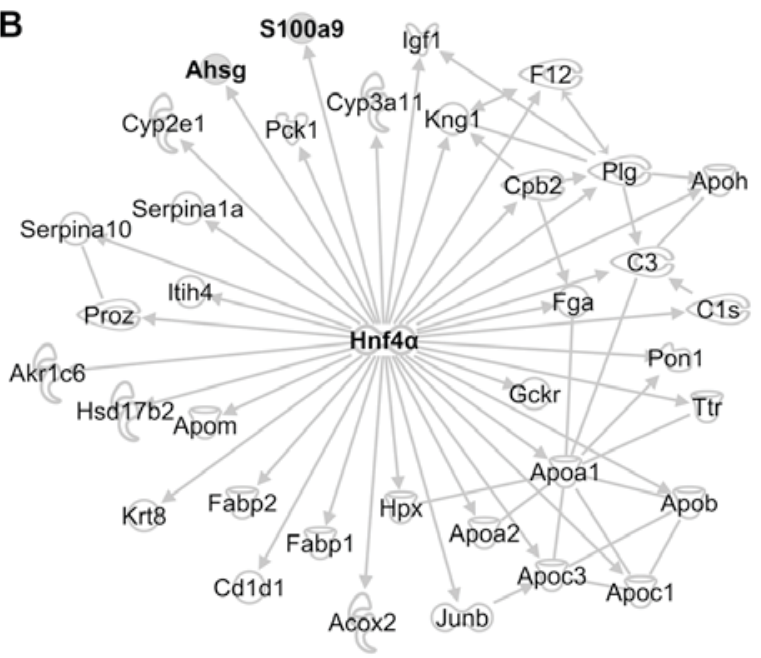

Figure 1. Upregulation of $H n f 4 \alpha$ in the depressive state affects a number of genes associated with physiological homeostasis. (A) Interactions between $H n f 4 \alpha$ and 5 genes in the PFC (F2, Igfl, Plg, Ttr and Serpina 3$)$ extracted from IPA results. (B) $H n f 4 \alpha$ regulates a number of genes that were also upor downregulated in the depressive state. Among these genes, the present study focused on S100a9 and Ahsg (in bold), as they can be measured in patients' serum. Hnf $4 \alpha$, hepatocyte nuclear factor $4 \alpha$; PFC, prefrontal cortex; $F 2$, coagulation factor II; $I g f 1$, insulin-like growth factor 1; Plg, plasminogen; $T t r$, transthyretin; Serpina3, serine (or cysteine) peptidase inhibitor, clade A, member 3; IPA, Ingenuity Pathway Analysis; S100a9, S100 calcium-binding protein A9; Ahsg, a2-HS-glycoprotein.

with MDD $(18,26,27)$. In addition, postmortem studies of depressed patients have revealed morphometric changes, such as smaller sized cell bodies in PFC regions (28). Ttr mRNA in the PFC was higher in CMS with analgesia models, which is consistent with the finding that serum levels of TTR
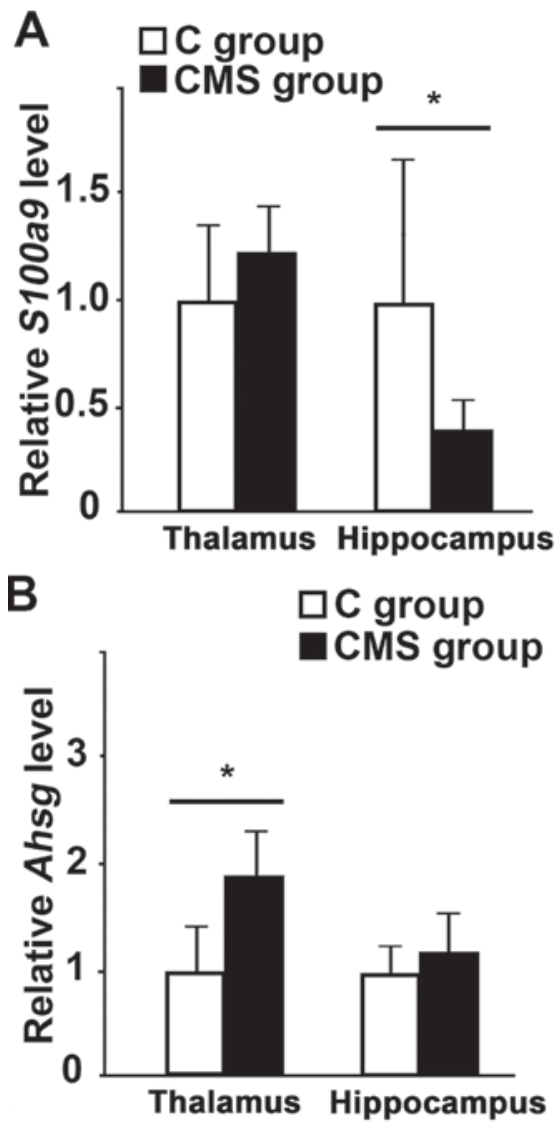

Figure 2. Enhanced expression of $S 100 a 9$ and Ahsg in the thalamus and hippocampus. RT-qPCR was performed to determine (A) S100a9 and (B) Ahsg expression levels in the thalamus and hippocampus ( $\mathrm{n}=7$ samples/group). The mean concentration of mRNA from the brains of the $\mathrm{C}$ group was set to 1 , and the relative mRNA levels in each brain region are expressed as the mean multiplicity of the CMS group relative to the $\mathrm{C}$ group. ${ }^{*} \mathrm{P}<0.05$ vs. $\mathrm{C}$ group. S100a9, S100 calcium-binding protein A9; Ahsg, a2-HS-glycoprotein; RT-qPCR, reverse transcription-quantitative polymerase chain reaction; C group, control group; CMS group, chronic mildly stressed group.

in patients with depression were higher compared with those of healthy people $(29,30)$. In addition, Igfl, Plg, Serpina 3 and Ttr were affected by Hnf4a (Fig. 1A) (31-35). These results indicated that $I g f 1, P l g$, Serpina 3 , and Ttr, which are strongly regulated by $H n f 4 \alpha$, and $F 2$ may affect the molecular mechanism of MDD development in the PFC.

S100a9 in the hippocampus is affected by exposure to chronic or repeated social stress, which may promote the migration of leukocytes to the brain $(36,37)$. In addition to regulating inflammation, $5100 \mathrm{a} 9$ also regulates responses to fibrosis, arteriosclerosis and infarction (38-43). S100A9 levels in the CMS group were higher compared with those in the $\mathrm{C}$ group, which was consistent with the mRNA levels in the PFC. In the hippocampus, S100A9 levels in the CMS group were higher compared with those in the $\mathrm{C}$ group, which was inconsistent with the mRNA levels. According to the Allen Brain Atlas (http://mouse.brain-map.org/), S100a9 is expressed at low levels in the hippocampal formation and thalamus of a normal mouse (http://mouse.brain-map. org/gene/show/19965) (44). S100A9, which is regulated by $H n f 4 \alpha$ was upregulated in the PFC and hippocampus $(18,32)$. Thus, S100a9/S100A9 may be upregulated in the depressive state through $H n f 4 \alpha / H N F 4 A$. This suggests that 
A

PFC

C CMS

IGF1
TTR
ACTB

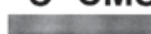

-

$B$

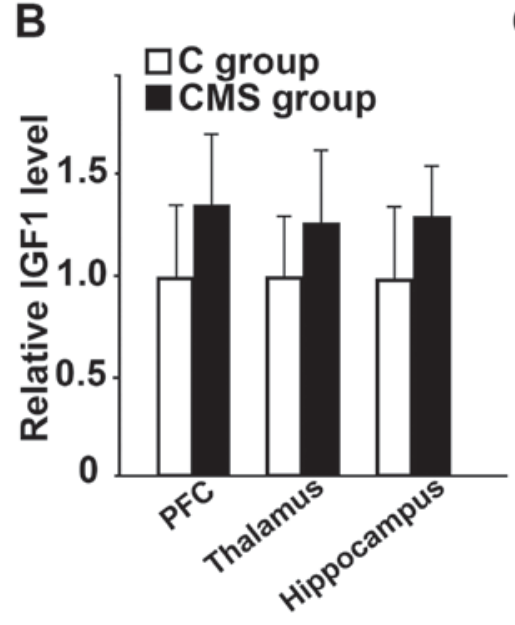

Thalamus

C CMS

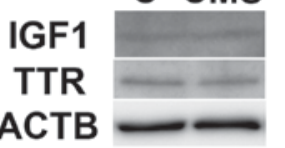

\section{Hippocampus}

C CMS

IGF1

TTR

АCTB

C

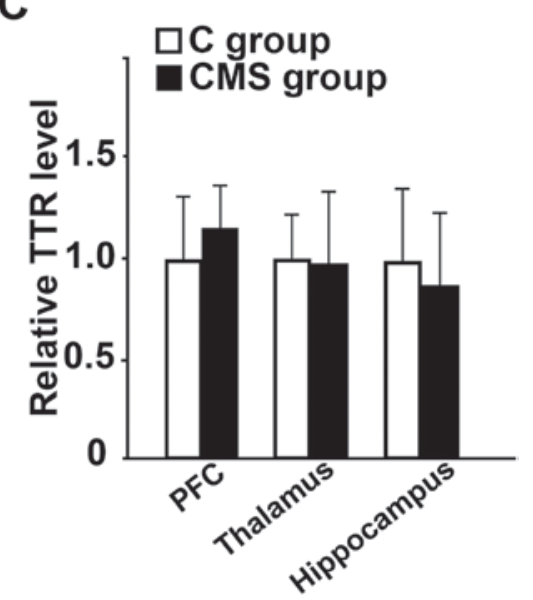

Figure 3. Expression of IGF1 and TTR proteins in the brains of C and CMS group mice. (A) Protein extracts were prepared from the PFC, thalamus and hippocampus of CMS and C group animals. The density of IGF1 and TTR bands were normalized to that of ACTB. The levels of (B) IGF1 and (C) TTR proteins in the three brain regions were compared, and no significant differences were observed between the CMS and $\mathrm{C}$ groups ( $\mathrm{n}=5$ samples/group). $\mathrm{C}$ group, control group; CMS group, chronic mildly stressed group. IGF1, insulin-like growth factor 1; TTR, transthyretin; C group, control group; CMS group, chronic mildly stressed group; ACTB, $\beta$-actin.

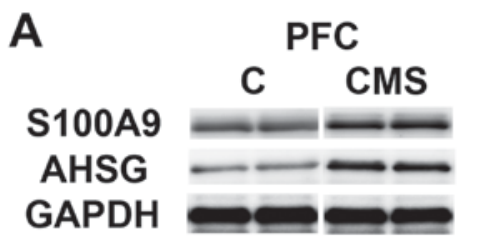

B

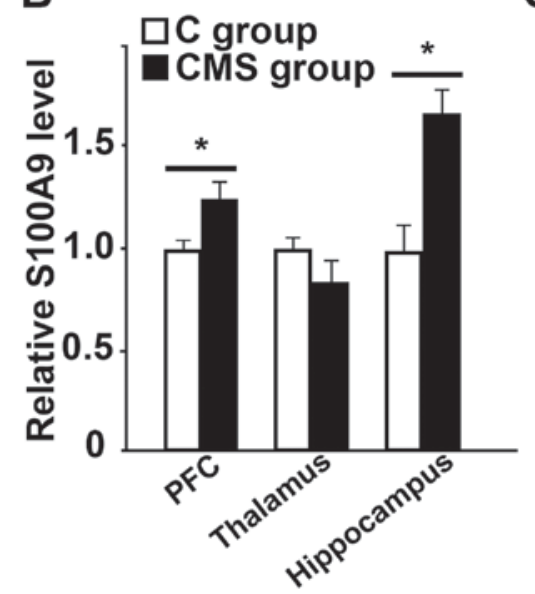

Thalamus

Hippocampus
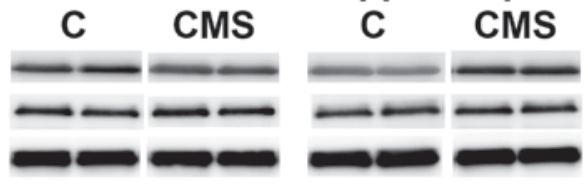

C

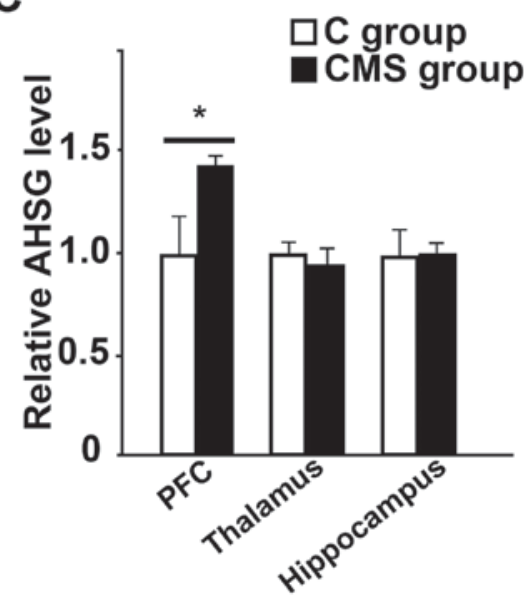

Figure 4. Expression of S100A9 and AHSG proteins in the brains of CMS and C group mice. (A) Protein extracts were prepared from the PFC, thalamus, and hippocampus of the CMS and C group animals. The densities of the S100A9 and AHSG bands were normalized to that of GAPDH. (B) The levels of S100A9 protein in the three brain regions were compared, and significant differences were observed in the PFC and hippocampus between the $\mathrm{CMS}$ and $\mathrm{C}$ groups. ${ }^{*} \mathrm{P}<0.05$ vs. $\mathrm{C}$ group ( $\mathrm{n}=3$ samples/group). (C) The same analysis was performed for AHSG and significant differences were observed in the PFC. ${ }^{*} \mathrm{P}<0.05$ vs. C group. S100A9, S100 calcium-binding protein A9; AHSG, $\alpha 2$-HS-glycoprotein; C group, control group; CMS group, chronic mildly stressed group; PFC, prefrontal cortex.

S100a9/S100A9 may have a role in chronic social stress and also in the development of physical diseases, such as inflammation or ischemia of the brain.
Clinical research has revealed a significant association between Ahsg and cognitive dysfunctions that are frequently observed in patients with MDD (45). Ahsg was categorized in 
immune disorders, and also in physical functions of glucose and lipid homeostasis $(46,47)$. Our previous results indicated that the CMS model had hypertriglycemia, and that there may be a significant association between MDD and metabolic disorders (18). The present study revealed that Ahsg levels in the PFC and thalamus of the CMS group were higher compared with those of the $\mathrm{C}$ group (Fig. 2B). According to the Allen Brain Atlas (http://mouse.brain-map.org/), Ahsg is expressed at relatively low levels in a normal mouse cortex and thalamus (http://mouse.brain-map.org/gene/show/11412) (44). In addition, there were significant group differences in the level of AHSG in the PFC, similar to those of HNF4A (18). Thus, AHSG may affect physiological homeostasis and lead to physical diseases, such as metabolic disorders, under MDD conditions.

In a meta-analysis of clinical studies, levels of interleukin (IL)-6 and tumor necrosis factor (TNF)- $\alpha$ were significantly higher in patients with MDD when compared with those in normal controls (13). This finding supports a potentially close association between MDD and the inflammatory response. In our previous study, levels of inflammatory cytokines, such as IL-5 and TNF- $\alpha$, were higher in the CMS group when compared with those in the $\mathrm{C}$ group (18). These results were consistent with previous findings from clinical and animal studies, and support the occurrence of inflammation during the course of MDD $(13,48)$. In addition, a clinical study revealed that serum S100A9 levels were greater in patients with an autoimmune disorder or rheumatoid arthritis when compared with healthy controls (41). From the IPA results, S100a9, Tnfo and Il12 may regulate each other (49-51), which further supports the close association between MDD and the inflammatory response. As serum AHSG levels are associated with the probability of metabolic syndrome and insulin resistance $(52,53)$, these two molecules may increase the risk of developing physical diseases in patients with MDD.

Regarding the limitations of the present study, S100A9 and AHSG were measured in only three brain regions in an animal model. To more thoroughly examine our hypotheses and to verify clinical relevance, particularly in association with physiological functions, metabolism should be analyzed in peripheral organs. In addition, measurement of the S100A9 and AHSG serum levels in this model would clarify the interactions between depression and other diseases; however, this was not possible in the present study due to a lack of serum. Therefore, further studies are required to evaluate these roles and the potential associations between other molecules associated with MDD and physiological homeostasis, including lipid metabolism or immune reactions. Finally, Serpina 3 was not measured by RT-qPCR, as different subtypes were detected multiple times on the microarray (GSE49867 on the Gene Expression Omnibus web page; https://www.ncbi.nlm.nih. gov/geo/query/acc.cgi?acc=GSE49867).

In conclusion, the present study demonstrated that a number of molecules directly regulated by $H n f 4 \alpha$ in the PFC may be closely associated with the development of MDD. S100A9 and AHSG were clearly expressed in the brain and may link depression with physiological homeostasis. Though there were a number of limitations in the present study, the results may help to clarify the mechanism mediating the interactions between MDD and physiological homeostasis in humans.

\section{Acknowledgements}

The authors would like to thank Mr Nobutaka Okamura (Department of Neuropsychiatry, Hyōgo College of Medicine, Hyōgo, Japan), Mrs. Naomi Gamachi (Laboratory of Tumor Immunology and Cell Therapy, Hyōgo College of Medicine, Hyōgo, Japan) and Ms. Emi Yamaguchi (Laboratory of Tumor Immunology and Cell Therapy, Hyōgo College of Medicine, Hyōgo, Japan) for their technical support; Mr Nobutaka Okamura for his assistance in the care of animals and collection of samples, Mrs. Naomi Gamachi for skilled western blotting, and Ms. Emi Yamaguchi for RNA purification and clerical support. In addition, the authors are grateful to the staff in the Research Facilities for Common Use, Hyōgo College of Medicine (Hyōgo, Japan), for allowing the use of their resources for RT-qPCR and western blotting. Finally, the authors thank the editing staff of Edanz Group Japan (Fukuoka, Japan) for their editorial support and proofreading.

\section{References}

1. Health Statistics Office, Vital, Health and Social Statistics Division. Patient Survey. Ministry of Health, Labour and Welfare, Japan. 2011. Available: http://www.mhlw.go.jp/english/database/db-hss/ps.html

2. Ministry of Health, Labour and Welfare. Health, Labour and Welfare Report. Ministry of Health, Labour and Welfare, Japan. 2010. Available: http://www.mhlw. go.jp/english/wp/wp-hw5/index.html

3. Slattery DA, Hudson AL and Nutt DJ: Invited review: The evolution of antidepressant mechanisms. Fundam Clin Pharmacol 18: 1-21, 2004.

4. Young EA and Korszun A: The hypothalamic-pituitary-gonadal axis in mood disorders. Endocrinol Metab Clin North Am 31: 63-78, 2002.

5. Paizanis E, Hamon M and Lanfumey L: Hippocampal neurogenesis, depressive disorders, and antidepressant therapy. Neural Plast 2007: 73754, 2007.

6. Diener C, Kuehner C, Brusniak W, Ubl B, Wessa M and Flor H: A meta-analysis of neurofunctional imaging studies of emotion and cognition in major depression. Neuroimage 61: 677-685, 2012.

7. Sawyer K, Corsentino E, Sachs-Ericsson N and Steffens DC: Depression, hippocampal volume changes, and cognitive decline in a clinical sample of older depressed outpatients and non-depressed controls. Aging Ment Health 16: 753-762, 2012.

8. Schiepers OJ, Wichers MC and Maes M: Cytokines and major depression. Prog Neuropsychopharmacol Biol Psychiatry 29: 201-217, 2005.

9. Slavich GM and Irwin MR: From stress to inflammation and major depressive disorder: A social signal transduction theory of depression. Psychol Bull 140: 774-815, 2014.

10. Oxenkrug GF: Tryptophan kynurenine metabolism as a common mediator of genetic and environmental impacts in major depressive disorder: The serotonin hypothesis revisited 40 years later. Isr J Psychiatry Relat Sci 47: 56-63, 2010.

11. Hage MP and Azar ST: The link between thyroid function and depression. J Thyroid Res 2012: 590648, 2012.

12. Ross DA and Cetas JS: Steroid psychosis: A review for neurosurgeons. J Neurooncol 109: 439-447, 2012.

13. Dowlati Y, Herrmann N, Swardfager W, Liu H, Sham L, Reim EK and Lanctôt KL: A meta-analysis of cytokines in major depression. Biol Psychiatry 67: 446-457, 2010.

14. Karege F, Perret G, Bondolfi G, Schwald M, Bertschy G and Aubry JM: Decreased serum brain-derived neurotrophic factor levels in major depressed patients. Psychiatry Res 109: 143-148, 2002.

15. Shimizu E, Hashimoto K, Okamura N, Koike K, Komatsu N, Kumakiri C, Nakazato M, Watanabe H, Shinoda N, Okada S and Iyo M: Alterations of serum levels of brain-derived neurotrophic factor (BDNF) in depressed patients with or without antidepressants. Biol Psychiatry 54: 70-75, 2003. 
16. Pedersen BK: Special feature for the Olympics: Effects of exercise on the immune system: Exercise and cytokines. Immunol Cell Biol 78: 532-535, 2000.

17. Chung S, Son GH and Kim K: Circadian rhythm of adrenal glucocorticoid: Its regulation and clinical implications. Biochim Biophys Acta 1812: 581-591, 2011.

18. Yamanishi K, Doe N, Sumida M, Watanabe Y, Yoshida M, Yamamoto $\mathrm{H}, \mathrm{Xu} \mathrm{Y}, \mathrm{Li} \mathrm{W}$, Yamanishi $\mathrm{H}$, Okamura $\mathrm{H}$ and Matsunaga $\mathrm{H}$ : Hepatocyte nuclear factor 4 alpha is a key factor related to depression and physiological homeostasis in the mouse brain. PLoS One 10: e0119021, 2015.

19. Yamanishi K, Maeda S, Kuwahara-Otani S, Watanabe Y, Yoshida M, Ikubo K, Okuzaki D, El-Darawish Y, Li W, Nakasho K, et al: Interleukin-18-deficient mice develop dyslipidemia resulting in nonalcoholic fatty liver disease and steatohepatitis. Transl Res 173: 101-114.e7, 2016.

20. Stein TD, Anders NJ, DeCarli C, Chan SL, Mattson MP and Johnson JA: Neutralization of transthyretin reverses the neuroprotective effects of secreted amyloid precursor protein (APP) in APPSW mice resulting in tau phosphorylation and loss of hippocampal neurons: Support for the amyloid hypothesis. J Neurosci 24: 7707-7717, 2004.

21. Yadav A, Kalita A, Dhillon S and Banerjee K: JAK/STAT3 pathway is involved in survival of neurons in response to insulin-like growth factor and negatively regulated by suppressor of cytokine signaling-3. J Biol Chem 280: 31830-31840, 2005.

22. Zheng WH, Kar S and Quirion R: Insulin-like growth factor-1-induced phosphorylation of transcription factor FKHRL1 is mediated by phosphatidylinositol 3-kinase/Akt kinase and role of this pathway in insulin-like growth factor-1-induced survival of cultured hippocampal neurons. Mol Pharmacol 62: 225-233, 2002.

23. Padmanabhan J, Levy M, Dickson DW and Potter $\mathrm{H}$ : Alpha1-antichymotrypsin, an inflammatory protein overexpressed in Alzheimer's disease brain, induces tau phosphorylation in neurons. Brain 129: 3020-3034, 2006.

24. Tsirka SE, Rogove AD, Bugge TH, Degen JL and Strickland S: An extracellular proteolytic cascade promotes neuronal degeneration in the mouse hippocampus. J Neurosci 17: 543-552, 1997.

25. Donovan FM, Pike CJ, Cotman CW and Cunningham DD: Thrombin induces apoptosis in cultured neurons and astrocytes via a pathway requiring tyrosine kinase and RhoA activities. J Neurosci 17: 5316-5326, 1997.

26. Geiser F, Conrad R, Imbierowicz K, Meier C, Liedtke R, Klingmüller D, Oldenburg $\mathrm{J}$ and Harbrecht U: Coagulation activation and fibrinolysis impairment are reduced in patients with anxiety and depression when medicated with serotonergic antidepressants. Psychiatry Clin Neurosci 65: 518-525, 2011.

27. Schroeder V, Borner U, Gutknecht S, Schmid JP, Saner H and Kohler HP: Relation of depression to various markers of coagulation and fibrinolysis in patients with and without coronary artery disease. Eur J Cardiovasc Prev Rehabil 14: 782-787, 2007.

28. Kang HJ, Voleti B, Hajszan T, Rajkowska G, Stockmeier CA, Licznerski P, Lepack A, Majik MS, Jeong LS, Banasr M, et al: Decreased expression of synapse-related genes and loss of synapses in major depressive disorder. Nat Med 18: 1413-1417, 2012

29. Frye MA, Nassan M, Jenkins GD, Kung S, Veldic M, Palmer BA, Feeder SE, Tye SJ, Choi DS and Biernacka JM: Feasibility of investigating differential proteomic expression in depression: Implications for biomarker development in mood disorders. Transl Psychiatry 5: e689, 2015.

30. Lisowski P, Wieczorek M, Goscik J, Juszczak GR, Stankiewicz AM, Zwierzchowski L and Swiergiel AH: Effects of chronic stress on prefrontal cortex transcriptome in mice displaying different genetic backgrounds. J Mol Neurosci 50: 33-57, 2013.

31. Kang X, Song Z, McClain CJ, Kang YJ and Zhou Z: Zinc supplementation enhances hepatic regeneration by preserving hepatocyte nuclear factor-4alpha in mice subjected to long-term ethanol administration. Am J Pathol 172: 916-925, 2008.

32. Odom DT, Zizlsperger N, Gordon DB, Bell GW, Rinaldi NJ, Murray HL, Volkert TL, Schreiber J, Rolfe PA, Gifford DK, et al: Control of pancreas and liver gene expression by HNF transcription factors. Science 303: 1378-1381, 2004

33. Naiki T, Nagaki M, Shidoji Y,Kojima H,Imose M, Kato T, Ohishi N, Yagi K and Moriwaki H: Analysis of gene expression profile induced by hepatocyte nuclear factor 4alpha in hepatoma cells using an oligonucleotide microarray. J Biol Chem 277: 14011-14019, 2002.

34. Späth GF and Weiss MC: Hepatocyte nuclear factor 4 expression overcomes repression of the hepatic phenotype in dedifferentiated hepatoma cells. Mol Cell Biol 17: 1913-1922, 1997.
35. Costa RH, Van Dyke TA, Yan C, Kuo F and Darnell JE Jr: Similarities in transthyretin gene expression and differences in transcription factors: Liver and yolk sac compared to choroid plexus. Proc Natl Acad Sci USA 87: 6589-6593, 1990.

36. Stankiewicz AM, Goscik J, Majewska A, Swiergiel AH and Juszczak GR: The effect of acute and chronic social stress on the hippocampal transcriptome in mice. PLoS One 10: e0142195, 2015.

37. Wohleb ES, Powell ND, Godbout JP and Sheridan JF: Stress-induced recruitment of bone marrow-derived monocytes to the brain promotes anxiety-like behavior. J Neurosci 33: 13820-13833, 2013.

38. Li C, Li S, Jia C, Yang L, Song Z and Wang Y: Low concentration of S100A8/9 promotes angiogenesis-related activity of vascular endothelial cells: Bridges among inflammation, angiogenesis, and tumorigenesis? Mediators Inflamm 2012: 248574, 2012.

39. Croce K, Gao H, Wang Y, Mooroka T, Sakuma M, Shi C, Sukhova GK, Packard RR, Hogg N, Libby P and Simon DI: Myeloid-related protein-8/14 is critical for the biological response to vascular injury. Circulation 120: 427-436, 2009.

40. de Seny D, Fillet M, Ribbens C, Marée R, Meuwis MA, Lutteri L, Chapelle JP, Wehenkel L, Louis E, Merville MP and Malaise M: Monomeric calgranulins measured by SELDI-TOF mass spectrometry and calprotectin measured by ELISA as biomarkers in arthritis. Clin Chem 54: 1066-1075, 2008

41. Sinz A, Bantscheff M, Mikkat S, Ringel B, Drynda S, Kekow J, Thiesen HJ and Glocker MO: Mass spectrometric proteome analyses of synovial fluids and plasmas from patients suffering from rheumatoid arthritis and comparison to reactive arthritis or osteoarthritis. Electrophoresis 23: 3445-3456, 2002.

42. Trendelenburg G: Molecular regulation of cell fate in cerebral ischemia: Role of the inflammasome and connected pathways. J Cereb Blood Flow Metab 34: 1857-1867, 2014.

43. Nagareddy PR, Murphy AJ, Stirzaker RA, Hu Y, Yu S, Miller RG, Ramkhelawon B, Distel E, Westerterp M, Huang LS, et al: Hyperglycemia promotes myelopoiesis and impairs the resolution of atherosclerosis. Cell Metab 17: 695-708, 2013.

44. Lein ES, Hawrylycz MJ, Ao N, Ayres M, Bensinger A, Bernard A, Boe AF, Boguski MS, Brockway KS, Byrnes EJ, et al: Genome-wide atlas of gene expression in the adult mouse brain. Nature 445: 168-176, 2007.

45. Laughlin GA, McEvoy LK, Barrett-Connor E, Daniels LB and Ix JH: Fetuin-A, a new vascular biomarker of cognitive decline in older adults. Clin Endocrinol (Oxf) 81: 134-140, 2014.

46. Biswas S, Sharma S, Saroha A, Bhakuni DS, Malhotra R, Zahur M, Oellerich M, Das HR and Asif AR: Identification of novel autoantigen in the synovial fluid of rheumatoid arthritis patients using an immunoproteomics approach. PLoS One 8: e56246, 2013

47. Mathews ST, Singh GP, Ranalletta M, Cintron VJ, Qiang X, Goustin AS, Jen KL, Charron MJ, Jahnen-Dechent W and Grunberger G: Improved insulin sensitivity and resistance to weight gain in mice null for the Ahsg gene. Diabetes 51: 2450-2458,2002

48. You Z, Luo C, Zhang W, Chen Y, He J, Zhao Q, Zuo R and Wu Y: Pro- and anti-inflammatory cytokines expression in rat's brain and spleen exposed to chronic mild stress: Involvement in depression. Behav Brain Res 225: 135-141, 2011.

49. Lee SY, Jung YO, Kim DJ, Kang CM, Moon YM, Heo YJ, Oh HJ, Park SJ, Yang SH, Kwok SK, et al: IL-12p40 homodimer ameliorates experimental autoimmune arthritis. J Immunol 195: 3001-3010, 2015.

50. Nakajima K, Kanda T, Takaishi M, Shiga T, Miyoshi K, Nakajima H, Kamijima R, Tarutani M, Benson JM, Elloso MM, et al: Distinct roles of IL-23 and IL-17 in the development of psoriasis-like lesions in a mouse model. J Immunol 186: 4481-4489, 2011.

51. Sunahori K, Yamamura M, Yamana J, Takasugi K, Kawashima M, Yamamoto H, Chazin WJ, Nakatani Y, Yui S and Makino H: The S100A8/A9 heterodimer amplifies proinflammatory cytokine production by macrophages via activation of nuclear factor kappa B and p38 mitogen-activated protein kinase in rheumatoid arthritis. Arthritis Res Ther 8: R69, 2006.

52. Xu Y, Xu M, Bi Y, Song A, Huang Y, Liu Y, Wu Y, Chen Y, Wang W, Li X and Ning G: Serum fetuin-A is correlated with metabolic syndrome in middle-aged and elderly Chinese. Atherosclerosis 216: 180-186, 2011.

53. Ishibashi A, Ikeda Y, Ohguro T, Kumon Y, Yamanaka S, Takata H, Inoue M, Suehiro T and Terada Y: Serum fetuin-A is an independent marker of insulin resistance in Japanese men. J Atheroscler Thromb 17: 925-933, 2010. 